\title{
A Single-Phase Reduced Component Count Asymmetrical Multilevel Inverter Topology
}

Yeganeh, Mohammad Sadegh Orfi; Davari, Pooya; Chub, Andrii; Mijatovic, Nenad; Dragicevic, Tomislav; Blaabjerg, Frede

Published in:

IEEE Journal of Emerging and Selected Topics in Power Electronics

Link to article, DOI:

10.1109/JESTPE.2021.3066396

Publication date:

2021

Document Version

Peer reviewed version

Link back to DTU Orbit

Citation (APA):

Yeganeh, M. S. O., Davari, P., Chub, A., Mijatovic, N., Dragicevic, T., \& Blaabjerg, F. (2021). A Single-Phase Reduced Component Count Ásymmetrical Multilevel Inverter Topology. IEEE Journal of Emerging and Selected Topics in Power Electronics, 9(6), 6780 - 6790. https://doi.org/10.1109/JESTPE.2021.3066396

\section{General rights}

Copyright and moral rights for the publications made accessible in the public portal are retained by the authors and/or other copyright owners and it is a condition of accessing publications that users recognise and abide by the legal requirements associated with these rights.

- Users may download and print one copy of any publication from the public portal for the purpose of private study or research.

- You may not further distribute the material or use it for any profit-making activity or commercial gain

- You may freely distribute the URL identifying the publication in the public portal 


\title{
A Single-Phase Reduced Component Count Asymmetrical Multilevel Inverter Topology
}

\author{
Mohammad Sadegh Orfi Yeganeh, Student Member, IEEE, Pooya Davari, Senior Member, IEEE, \\ Andrii Chub, Senior Member, IEEE, Nenad Mijatovic, Senior Member, IEEE, \\ Tomislav Dragičević, Senior Member, IEEE, and Frede Blaabjerg, Fellow, IEEE
}

\begin{abstract}
Multilevel inverters (MLIs) have gained wide attention in industry and academia to provide higher voltage levels with lower harmonics, power losses, and cost. This study proposes a new asymmetrical MLI topology with reduced component count (RCC). The proposed topology can be extended in a threephase structure and both modular and cascaded configurations to generate the required number of voltage levels for high-voltage applications. To minimize the power losses and the voltage stress on the switches, this configuration has the potential to produce negative polarity without an H-bridge configuration, thereby the active switches are reduced to only three switches in the conduction path. Due to the possibility of applying different switching patterns, this paper proposes a new solution by employing particle swarm optimization (PSO) algorithm to determine the optimized DC sources' magnitude. To improve the voltage quality and minimize the total harmonic distortion (THD), the optimal switching angle (OSA) modulation technique is applied to determine the optimum switching angles by PSO algorithm. Moreover, the proposed topology's effectiveness compared to the conventional cascaded H-bridge (CHB) MLI with 15-levels is illustrated by providing comparative results that express fewer power losses. Finally, the proposed topology's feasibility and its optimization approach are validated by a single-phase prototype utilizing 15- and 25-levels.
\end{abstract}

Index Terms-Multilevel Inverter (MLI), Optimal Switching Angle (OSA), Particle Swarm Optimization (PSO), Reduced Component Count (RCC), Total Harmonic Distortion (THD).

\section{INTRODUCTION}

$\mathbf{M}$ ULTILEVEL inverters (MLIs) have been used as a solution for voltage rating limitation of power semiconductors while improving the output power and voltage qualities. With the advent of MLIs, there is a decrease in voltage stress across power switches, switching losses, total harmonic distortion (THD), expensive and bulky filters, electromagnetic interference, and better output characteristics than the conventional two-level inverters. MLIs have important roles in various advanced power conversion applications, like renewable energy systems (standalone and grid-connected),

Manuscript received Month xx, 2xxx; revised Month xx, xxxx; accepted Month $\mathrm{x}, \mathrm{xxxx}$. This work was supported in part by the $\mathrm{xxx}$ Department of xxx under Grant (sponsor and financial support acknowledgment goes here).

(Authors' names and affiliation) First A. Author1 and Second B. Author2 are with the $\mathrm{xxx}$ Department, University of xxx, City, Zip code, Country, on leave from the National Institute for xxx, City, Zip code, Country (e-mail: author@domain.com)

Third C. Author3 is with the National Institute of xxx, City, Zip code, Country (corresponding author to provide phone: $\mathrm{xxx}-\mathrm{xxx}-\mathrm{xxxx}$; fax: $\mathrm{xxx}-$ xxx-xxxx; e-mail: author@ domain.gov). battery energy storage systems, variable frequency drives, electric vehicle drives, uninterruptible power supplies, etc. The most well-known conventional MLIs have three basic topologies, which are diode clamped (DC-MLI), flying capacitor (FC-MLI), and cascaded H-bridge (CHB-MLI) [1], [2].

The conventional MLIs required a high number of components to generate a staircase waveform. Reduced component count (RCC) MLI topologies are a solution for the drawbacks of the conventional MLIs. According to the generated output voltage polarities, RCC-MLIs are classified into two groups. The first group is a combination of the main structure and a series H-bridge unit, where the main section generates output voltage steps with positive polarity. On the other hand, using the H-bridge section allows for generating the negative voltage polarity [3]-[5]. The second group is RCC-MLIs with the main structure capable of providing both the positive and negative polarities [6]-[9]. The second group suits the most low- and medium-voltage applications, due to the lower voltage stress on the H-bridge switches that narrows down the applicability in high-voltage applications. In addition to the on-state switches in the main structure, the existence of two on-state switches in the H-bridge section leads to more power losses for the first group [10]. Increasing voltage quality by multiple DC sources leads to two definitions of symmetrical (equal) and asymmetrical (unequal) DC sources presented in the literature. To obtain higher levels for asymmetrical MLIs, some methods like binary, trinary, and other algorithms are available [11]-[13]. The MLI topology proposed in [14] has lower conduction losses than the CHB-MLI. Further, the numbers of switching patterns for different current paths do not increase at high-voltage levels. The MLIs proposed in [15], [16] are asymmetrical, which have the disadvantage of high total blocking voltage (TBV) due to their H-bridge sections. An abundance of switching patterns may increase reliability and fault-tolerance capability, change the current path, and keep the system normal after a fault occurs [17], [18]. Some RCC-MLI topologies have been briefly reviewed in [19]-[27].

Besides different topologies and configurations of power switches, different modulation strategies have been introduced as well. Some of them are more usable in industrial applications like selective harmonic elimination (SHE), space vector modulation (SVM), optimal switching angle (OSA) modulation at low frequencies [28]-[33], which can be applied with artificial intelligence algorithms to optimize the output voltage/current. It is an excellent solution to decrease the 


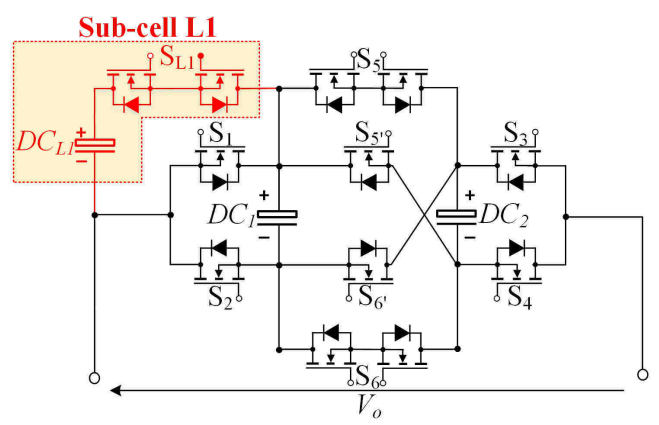

(a)

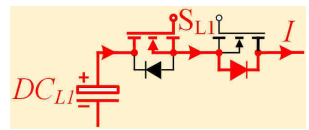

(b)

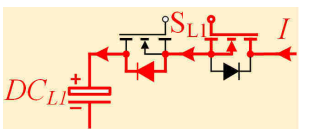

(c)
Fig. 1. Circuit diagram of the proposed single-phase MLI topology (a) 15level inverter of the generalized proposed topology with a sub-cell (L1), (b) and (c) Current directions in the sub-cell (L1).

control of computational burden [34]. Among these modulation strategies, fundamental-frequency modulation methods can provide better performance than high-frequency methods. Lower switching losses and more control on THD, and the amplitudes of output harmonics are the benefits of these methods.

This paper proposes a new asymmetrical reduced component count MLI topology with multiple DC sources and the ability to generate both the positive and negative voltage levels without the help of an additional series H-bridge section. The proposed MLI topology reduces the number of on-state switches to three active switches in each module's current loop to decrease the power losses and increase the total efficiency. It can be extended easily in a three-phase structure and both modular and cascaded connections too. By utilizing the PSO algorithm, an optimization procedure is proposed to determine the optimized voltage magnitudes of DC sources instead of using the standard algorithms (binary, trinary, and other algorithms) and mathematical operations. The paper is organized as follows: Section II presents the proposed MLI topology and its operating principles, Section III illustrates the employed OSA modulation strategy, Section IV discusses loss calculations in the proposed and the conventional CHBMLI, Section V depicts a comprehensive comparative study, Section VI is focused on simulation and experimental results of the proposed MLI topology prototype, and finally, Section VII draws the conclusion.

\section{Operating Principles of The Proposed MLi}

\section{A. Circuit Configuration}

A general schematic of the proposed topology is presented in Fig. 1(a), which consists of the main structure and a subcell. This configuration is a single-phase topology and is based on unequal DC sources. The proposed configuration can overcome the drawback of power losses and the cost of modular extension better in comparison with the topology proposed in [14]. By adding a sub-cell of one bidirectional
TABLE I

SWitching States of the Proposed 15-Level Inverter IN Fig. 1

\begin{tabular}{|c|c|c|c|c|c|c|c|c|c|c|c|}
\hline State & $S_{L 1}$ & $S_{1}$ & $S_{2}$ & $S_{3}$ & $S_{4}$ & $S_{5}$ & $S_{5^{\prime}}$ & $S_{6}$ & $S_{6^{\prime}}$ & $V_{\text {out }}$ & Voltage Level \\
\hline 1 & 0 & 1 & 0 & 0 & 1 & 0 & 0 & 0 & 1 & $+D C_{1}+D C_{2}$ & $+7 V_{D C}$ \\
\hline 2 & 1 & 0 & 0 & 0 & 1 & 0 & 0 & 0 & 1 & $+D C_{1}+D C_{2}-D C_{L 1}$ & $+6 V_{D C}$ \\
\hline \multirow{2}{*}{3} & 0 & 1 & 0 & 0 & 1 & 1 & 0 & 0 & 0 & \multirow{2}{*}{$+D C_{2}$} & \multirow{2}{*}{$+5 V_{D C}$} \\
\hline & 0 & 0 & 1 & 0 & 1 & 0 & 0 & 0 & 1 & & \\
\hline 4 & 1 & 0 & 0 & 0 & 1 & 1 & 0 & 0 & 0 & $+D C_{2}-D C_{L 1}$ & $+4 V_{D C}$ \\
\hline 5 & 0 & 0 & 1 & 0 & 1 & 1 & 0 & 0 & 0 & $-D C_{1}+D C_{2}$ & $+3 V_{D C}$ \\
\hline \multirow{2}{*}{6} & 0 & 1 & 0 & 1 & 0 & 0 & 0 & 0 & 1 & \multirow{2}{*}{$+D C_{1}$} & \multirow{2}{*}{$+2 V_{D C}$} \\
\hline & 0 & 1 & 0 & 0 & 1 & 0 & 0 & 1 & 0 & & \\
\hline \multirow[t]{2}{*}{7} & 1 & 0 & 0 & 1 & 0 & 0 & 0 & 0 & 1 & \multirow{2}{*}{$+D C_{1}-D C_{L 1}$} & \multirow{2}{*}{$+V_{D C}$} \\
\hline & 1 & 0 & 0 & 0 & 1 & 0 & 0 & 1 & 0 & & \\
\hline \multirow{4}{*}{8} & 0 & 1 & 0 & 1 & 0 & 1 & 0 & 0 & 0 & & \multirow{4}{*}{0} \\
\hline & 0 & 1 & 0 & 0 & 1 & 0 & 1 & 0 & 0 & & \\
\hline & 0 & 0 & 1 & 0 & 1 & 0 & 0 & 1 & 0 & & \\
\hline & 0 & 0 & 1 & 1 & 0 & 0 & 0 & 0 & 1 & & \\
\hline \multirow{2}{*}{9} & 1 & 0 & 0 & 1 & 0 & 1 & 0 & 0 & 0 & \multirow{2}{*}{$-D C_{L 1}$} & \multirow{2}{*}{$-V_{D C}$} \\
\hline & 1 & 0 & 0 & 0 & 1 & 0 & 1 & 0 & 0 & & \\
\hline \multirow{2}{*}{10} & 0 & 0 & 1 & 0 & 1 & 0 & 1 & 0 & 0 & \multirow{2}{*}{$-D C_{1}$} & \multirow{2}{*}{$-2 V_{D C}$} \\
\hline & 0 & 0 & 1 & 1 & 0 & 1 & 0 & 0 & 0 & & \\
\hline 11 & 0 & 1 & 0 & 1 & 0 & 0 & 0 & 1 & 0 & $+D C_{1}-D C_{2}$ & $-3 V_{D C}$ \\
\hline 12 & 1 & 0 & 0 & 1 & 0 & 0 & 0 & 1 & 0 & $+D C_{1}-D C_{2}-D C_{L 1}$ & $-4 V_{D C}$ \\
\hline \multirow{2}{*}{13} & 0 & 0 & 1 & 1 & 0 & 0 & 0 & 1 & 0 & \multirow{2}{*}{$-D C_{2}$} & \multirow{2}{*}{$-5 V_{D C}$} \\
\hline & 0 & 1 & 0 & 1 & 0 & 0 & 1 & 0 & 0 & & \\
\hline 14 & 1 & 0 & 0 & 1 & 0 & 0 & 1 & 0 & 0 & $-D C_{2}-D C_{1}$ & $-6 V_{D C}$ \\
\hline 15 & 0 & 0 & 1 & 1 & 0 & 0 & 1 & 0 & 0 & $-D C_{1}-D C_{2}$ & $-7 V_{D C}$ \\
\hline
\end{tabular}

power switches and one DC source, it is possible to increase the number of voltage levels. Fig. 1(b) and (c) show how the bidirectional switch in series with the DC source $\left(D C_{L 1}\right)$ can prevent short circuits by blocking current polarities. In this arrangement, there are only three active power semiconductors to generate the desired voltage level. So, the main advantage of the proposed topology is a reduction of conduction losses. The other benefits of the proposed configuration can be expressed as a reduction in component count that leading a decrease in control complexity and cost since it has no bulky passive elements like capacitors to be utilized to maintain the voltage levels. A 15-level inverter can be achieved by adding a subcell to the main structure. So, the structure consists of three voltage sources $\left(D C_{1}, D C_{2}\right.$, and $\left.D C_{L 1}\right)$, six unidirectional switches $\left(S_{1}, S_{2}, S_{3}, S_{4}, S_{5^{\prime}}\right.$, and $\left.S_{6^{\prime}}\right)$ and three bidirectional switches $\left(S_{L 1}, S_{5}\right.$, and $\left.S_{6}\right)$. Furthermore, combining two subcells would result in a 25 -level inverter. Assuming that the number of DC sources is $n_{D C}$, the number of required power switches $N_{S W}$ and gate-drivers $N_{\text {Driver }}$ can be defined for the proposed topology for $n_{D C} \geq 3$ as follows:

$$
\begin{gathered}
N_{S W}=2 n_{D C}+6 \\
N_{\text {Driver }}=n_{D C}+6
\end{gathered}
$$

\section{B. Operating Principles}

The possible switching states of the proposed 15-level inverter are listed in Table I. To achieve all the possible voltage levels (positive and negative), the DC sources' magnitudes should be considered as $D C_{1}=2 V_{D C}, D C_{2}=5 V_{D C}$, and $D C_{L 1}=V_{D C}$. According to Table I, there are twenty-four switching patterns to produce 15 steps in the output voltage. A large number of switching patterns lead to numerous available current paths. In all cases for the modular extension, only 


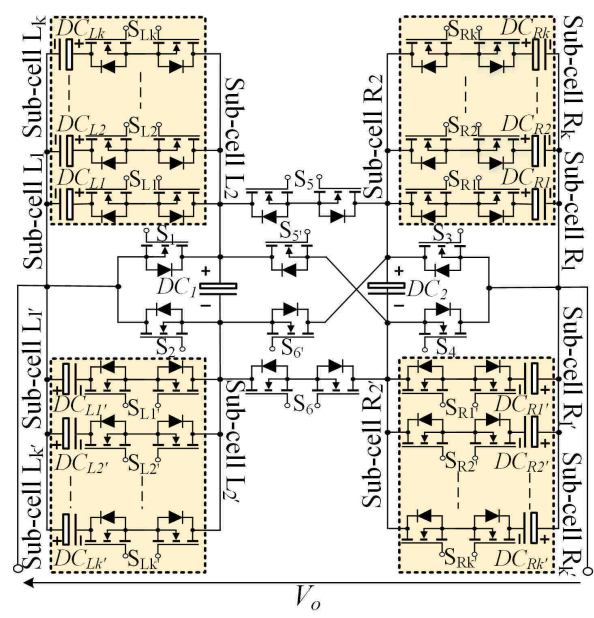

(a)

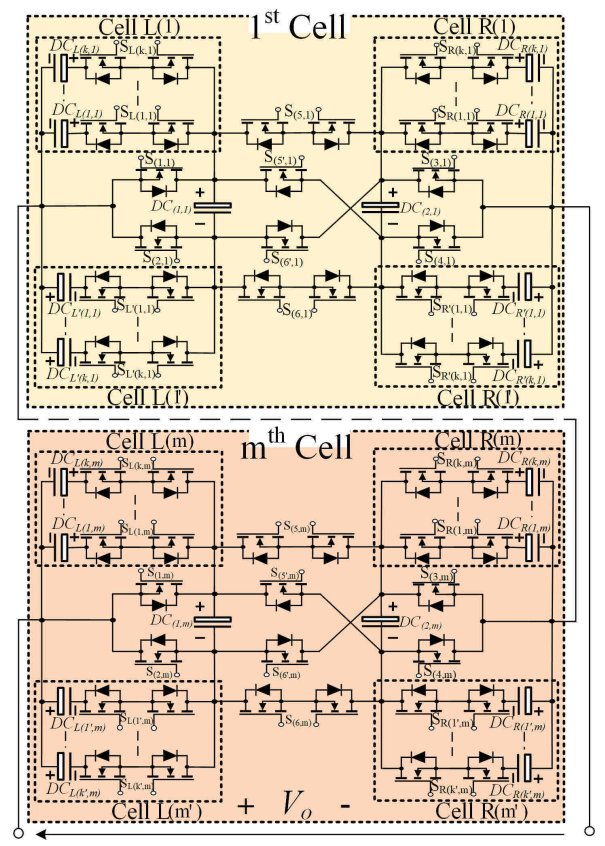

(b)

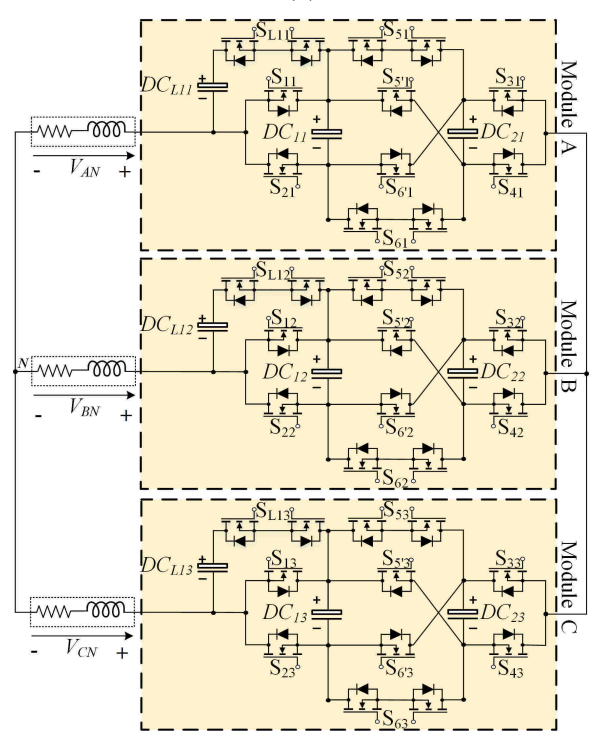

(c)

Fig. 2. Proposed MLI topology, (a) Single-phase modular extension, (b) Cascaded extension, and (c) Three-phase configuration. three on-state power switches are used as conducting routes to generate any voltage levels.

\section{Module Extension}

One of the merits of the proposed MLI structure is its capability to be extended in modular and cascaded connections to generate higher voltage levels. This particular feature has many benefits, and it is instrumental in high voltage applications, where there are many limitations on blocking voltage of each switch. A modular extension is provided easily by adding a sub-cell comprised of one bidirectional switch and one DC source. By adding a sub-cell to the mentioned structure in Fig. 1, it is possible to generate ten more levels in the output voltage and provide a 25 -levels inverter. The cascaded extension can be provided by a series connection of these modules. These sub-cells can be added in parallel with side switches $\left(S_{1}, S_{2}, S_{3}\right.$, and $\left.S_{4}\right)$ to generate more voltage levels. These sub-cells are labeled as $\left(L, L^{\prime}, R\right.$, and $\left.R^{\prime}\right)$. Fig. 2(a) presents a modular extension of the proposed MLI topology. This structure is synthesized by connecting more sub-cells in parallel to produce more voltage levels. At each module, only three switches are required to conduct the current and generate any voltage level. The topology followed in Fig. 2(b) is known as a cascaded extension comprising $m$ series cells. Each of the cells in modular configuration consists of $k$ number of subcells $(1<2<\ldots<j<\ldots<k)$. The switches $\left(S_{1}, S_{2}, S_{L k}\right.$, and $\left.S_{L k^{\prime}}\right)$ are on the left side, the switches $\left(S_{3}, S_{4}, S_{R k}\right.$, and $\left.S_{R k^{\prime}}\right)$ are on the right side, and $\left(S_{5}, S_{5^{\prime}}, S_{6}\right.$, and $\left.S_{6^{\prime}}\right)$ are in the center. They will not be turned on at the same time to avoid short circuit of $\left(D C_{1}, D C_{L k}\right.$, and $\left.D C_{L k^{\prime}}\right),\left(D C_{2}, D C_{R k}\right.$, and $\left.D C_{R k^{\prime}}\right)$, and $\left(D C_{1}\right.$ and $\left.D C_{2}\right)$ respectively. Likewise, an extension of the proposed MLI topology is possible for a three-phase configuration. In Fig. 2(c), a combination of three single-phase 15-level inverters (module A, module B, and module $\mathrm{C}$ ) of the proposed topology makes a three-phase MLI that are in series with loads in each phase. The same as single-phase, it is possible to derive both modular and cascaded extensions of the three-phase configuration too.

\section{Blocking Voltage and DC Voltage Sources Magnitude}

In asymmetrical MLIs, the DC sources' magnitudes are considered different to produce more output voltage levels than the symmetrical MLIs. A comprehensive mathematical formulation is provided for the standard algorithms to determine the optimum DC sources' magnitudes in many publications. A maximum voltage magnitude that a switch has to block in offstate is defined as the switch's blocking voltage. The sum of these voltage magnitudes of each switch in a converter is called TBV. This paper proposes a new solution to form the largest combination of input DC sources to achieve the maximum voltage levels rather than employing mathematical formulation or calculation algorithms. This approach will reduce TBV significantly. Table II presents the blocking voltage of switches for a 15-level inverter. The value of each switch's blocking voltage is considered a dependent and absolute parameter due to the employment of DC sources magnitude in both the positive and negative polarities arrangement for the optimization 


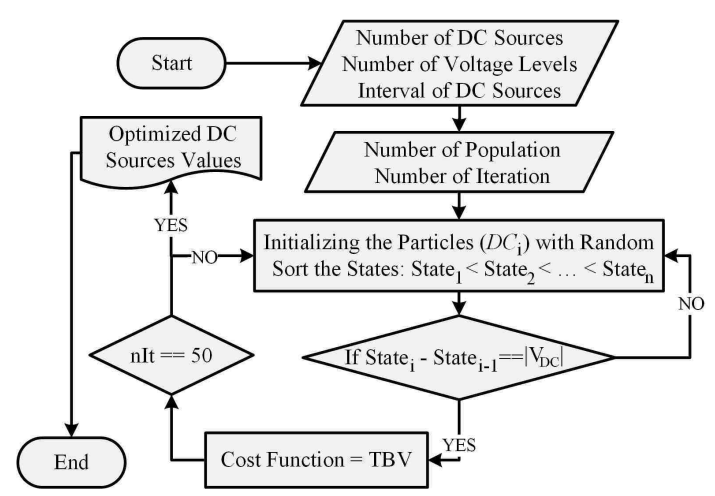

Fig. 3. Flow chart of the utilized optimization procedure for obtaining the optimized DC sources values using particle swarm optimization.

algorithm. For the proposed topology with modular extension, TBV of the individual switches can be expressed as:

$$
\begin{gathered}
V_{S 1}=\max \left(D C_{L k}, D C_{1},\left(D C_{1}-D C_{L k^{\prime}}\right)\right) \\
V_{S 2}=\max \left(D C_{L k^{\prime}}, D C_{1},\left(D C_{1}-D C_{L k}\right)\right) \\
V_{S 3}=\max \left(D C_{R k}, D C_{2},\left(D C_{2}-D C_{R k^{\prime}}\right)\right) \\
V_{S 4}=\max \left(D C_{R k^{\prime}}, D C_{2},\left(D C_{2}-D C_{R k}\right)\right) \\
V_{S 5}=V_{S 6}=\max \left(D C_{1}, D C_{2}\right) \\
V_{S 5^{\prime}}=V_{S 6^{\prime}}=D C_{1}+D C_{2} \\
V_{S L k}=\max _{\left(D C_{L k}, D C_{L k}-D C_{1}, D C_{L k}-D C_{L j}\right.} \\
\left.D C_{L k}+D C_{L k^{\prime}}\right) \\
V_{S L k^{\prime}}=\max _{L}\left(D C_{L k^{\prime}}, D C_{L k^{\prime}}-D C_{1}, D C_{L k^{\prime}}-D D_{L j^{\prime}}\right. \\
\left.D C_{L k^{\prime}}+D C_{L k}\right) \\
V_{S R k}=\max _{(}\left(D C_{R k}, D C_{R k}-D C_{2}, D C_{R k}-D C_{R j}\right. \\
\left.D C_{R k}+D C_{R k^{\prime}}\right) \\
V_{S R k^{\prime}}=\max _{R}\left(D C_{R k^{\prime}}, D C_{R k^{\prime}}-D C_{2}, D C_{R k^{\prime}}-D C_{R j^{\prime}}\right. \\
\left.D C_{R k^{\prime}}+D C_{R k}\right)
\end{gathered}
$$

DC sources are considered variable in both positive and negative ranges. In this way, the maximum value of TBV can be calculated for each switch. Finally, the TBV of the whole system can be calculated as follows:

TABLE II

Switch Blocking Voltage of the Proposed 15-LeVel InVerter

\begin{tabular}{cc}
\hline \hline Switch & Blocking Voltage Magnitude \\
\hline$S_{1}$ & $\max \left(D C_{L 1}, D C_{1}, D C_{1}-D C_{L 1}\right)$ \\
$S_{2}$ & $D C_{1}$ \\
$S_{3}$ & $D C_{2}$ \\
$S_{4}$ & $D C_{2}$ \\
$S_{5}$ & $\max \left(D C_{1}, D C_{2}\right)$ \\
$S_{5^{\prime}}$ & $D C_{1}+D C_{2}$ \\
$S_{6}$ & $\max \left(D C_{1}, D C_{2}\right)$ \\
$S_{6^{\prime}}$ & $D C_{1}+D C_{2}$ \\
$S_{L 1}$ & $\max \left(D C_{L 1}, D C_{L 1}-D C_{1}\right)$ \\
\hline \hline
\end{tabular}

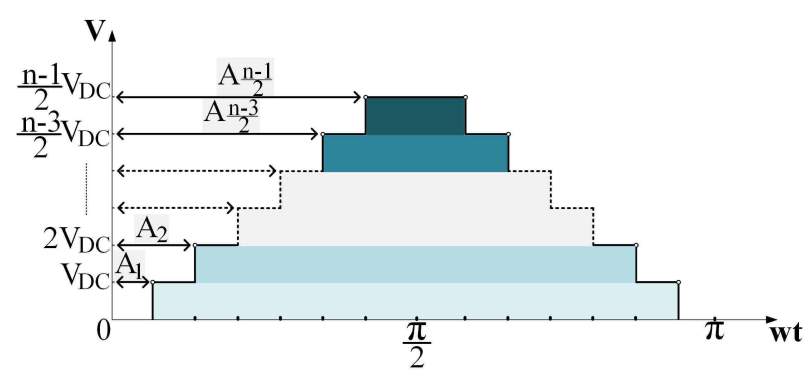

Fig. 4. Voltage waveform and switching angles of each level for an n-level inverter.

$$
\begin{aligned}
T B V= & V_{S 1}+V_{S 2}+V_{S 3}+V_{S 4}+2 V_{S 5}+2 V_{S 5^{\prime}} \\
& +V_{S L i}+V_{S R i}+V_{S L i^{\prime}}+V_{S R i^{\prime}} .
\end{aligned}
$$

Fig. 3 presents the optimization procedure to determine the magnitudes of the DC sources. At the beginning of this flowchart, the number of DC sources and the maximum number of the voltage level states are given. The maximum number of the possible voltage levels state can be obtained by considering the proposed topology's available arrangements. After that, the definition of the DC sources' intervals is the next step. For instance, intervals of the proposed n-level inverter are equal to $\left[\frac{-n}{2}, \frac{+n}{2}\right]$, and $n$ is the number of voltage levels. The absolute value of each switch's blocking voltage for the 15-level proposed configuration is considered in Table II. So, all the states of the DC sources' arrangement can be analyzed by keeping both the positive and the negative values (different polarities). According to the obtained results, iteration and population numbers are considered 50, suitable for this optimization. Each DC sources' arrangement is known as a state to achieve the proposed topology's desired output voltage. The output voltage value organizes all the switching states' arrangements (Table I). Suppose the difference between consecutive levels will not be equal to $\left|V_{D C}\right|$ (the nominal DC voltage), THD increases, and consequently, the quality of the output decreases. So, this constraint should be observed for all the states. This optimization procedure leads to a reduction in $\mathrm{TBV}$, which is considered as a cost function for this algorithm. At the end of this algorithm, the DC sources' optimized magnitudes are obtained for the proposed topology. Different MLI topologies can employ the optimization procedure of the proposed algorithm.

\section{Modulation Strategy}

In this paper, the optimal switching angle modulation technique is used to order the power switches. This technique works based on selecting the optimized switching angles to improve the output voltage quality. By using this technique, a reduction in switching losses and THD are achieved. Fig. 4 presents the selected switching angles at the first quarter cycle of the voltage waveform to make a symmetrical configuration with off-line calculations for an n-level inverter. In this way, there is no DC terms and even harmonics in the output voltage. The output voltage function based on Fourier analysis is as follows: 


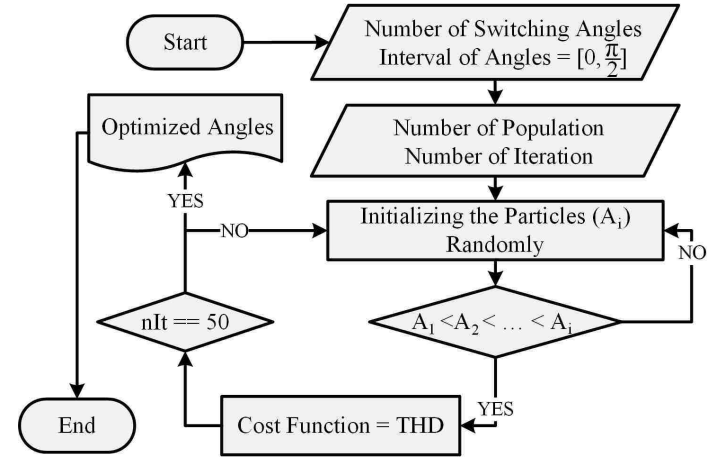

Fig. 5. Flow chart of the utilized optimization procedure to find the optimized angles using particle swarm optimization.

$$
\left\{\begin{array}{l}
V_{L 1}=\sum_{j=1,3,5}^{\infty} \frac{4 V_{D C}}{j \pi} \cos \left(j A_{1}\right) \\
V_{L 2}=\sum_{j=1,3,5}^{\infty} \frac{4 V_{D C}}{j \pi} \cos \left(j A_{2}\right) \\
\cdots \\
V_{L \frac{(n-1)}{2}}=\sum_{j=1,3,5}^{\infty} \frac{4 V_{D C}}{j \pi} \cos \left(j A_{\frac{(n-1)}{2}}\right) \\
V_{\text {out }}=V_{L 1}+V_{L 2}+\ldots+V_{L \frac{(n-1)}{2}}
\end{array}\right.
$$

The vector of the phase voltage is $V_{\text {out }}, V_{L i}$ is the voltage for $i^{\text {th }}$ level, and $A_{1}{ }^{\circ}, A_{2}{ }^{\circ}$, and $A^{\circ}{ }_{\left(\frac{n-1}{2}\right)}$ are the switching angles of first, second and $\left(\frac{n-1}{2}\right)^{t h}$ voltage levels respectively.

The value's difference of two consecutive levels is equal to $\left|V_{D C}\right|$. The optimization procedure of the mentioned modulation technique is presented in Fig. 5. Particle swarm optimization (PSO) algorithm is employed for this optimization procedure to minimize THD by selecting optimized switching angles.

At the beginning of this algorithm, the number of switching angles is determined based on the number of output voltage steps. This parameter is equal to $\frac{n-1}{2}$ (there is one angle at each level, as shown in Fig. 4). Intervals of the switching angles are considered $\left[\begin{array}{ll}0 & \frac{\pi}{2}\end{array}\right]$. The number of populations $n_{P O P}$ and the number of iterations $n_{I t}$ are equal to 50 . The constraints of switching angles value are $A_{1}{ }^{\circ}<A_{2}{ }^{\circ}<\ldots<A_{n}{ }^{\circ}$, which defines the condition for calculation of a Fourier series and consequent THD evaluation. The THD is considered as a cost function, and the mentioned algorithm has to minimize it as well. There are twelve switching angles for the proposed 25-level inverter. The optimized switching angles by this technique are presented in Table III (the angles are in degrees).

TABLE III

OPTIMIZED SWITCHING ANGLES FOR 25-LEVEL INVERTER

$\begin{array}{llllllllllllll}\text { Angle(degree) } & A_{1} & A_{2} & A_{3} & A_{4} & A_{5} & A_{6} & A_{7} & A_{8} & A_{9} & A_{10} & A_{11} & A_{12} & \mathrm{THD}_{\mathrm{V}}\end{array}$

\begin{tabular}{llllllllllllllll}
\hline OSA (PSO) & 2.5 & 7.2 & 11.7 & 16.8 & 21.8 & 26.8 & 32.0 & 38.0 & 44.5 & 51.2 & 59.7 & 71.0 & $3.2 \%$
\end{tabular}

$\begin{array}{llllllllllllll}\operatorname{Ref}[13] & 2.6 & 5.4 & 12.1 & 17.1 & 21.7 & 26.9 & 32.6 & 38.5 & 44.8 & 51.9 & 60.7 & 72.7 & 3.4 \%\end{array}$
The obtained THD from the OSA modulation technique in this study is better than the obtained optimum results in [13].

\section{LOSS CALCUlations}

Three groups of power losses exist in power converters: conduction, switching and blocking state (leakage) losses. Blocking state losses are neglected because they are small [10]. The prototype of the proposed MLI topology consists of power MOSFETs. The conduction losses for these switches can be calculated using a MOSFET-approximation with the drainsource on-state resistance $\left(R_{D S, \text { on }}\right)$. MOSFET conduction losses $\left(P_{c, M}\right)$ are the integration of the instantaneous power losses over a switching period $\left(T_{s w}\right)$, which gives an average value, as follows:

$$
P_{c, M}=\frac{1}{T_{s w}} \int_{0}^{T_{s w}} R_{D S, o n} \cdot i(t)_{D S}^{2} \cdot d t=R_{D S, o n} \cdot I_{D S, r m s}^{2}
$$

where $i_{D S}$ is the drain-source current and $I_{D S, r m s}$ is the root mean square value of the MOSFET on-state current.

The anti-parallel diode can be estimated using a diodeapproximation with a series connection of DC voltage source that represents the diode on-state in zero-current voltage. In addition, a diode on-state resistance $\left(R_{D}\right)$ is estimated to calculate the anti-parallel diode conduction losses $\left(P_{c, D}\right)$, as follows:

$$
\begin{aligned}
P_{c, D} & =\frac{1}{T_{s w}} \int_{0}^{T_{s w}}\left(V_{D}+R_{D} \cdot i_{F}(t)\right) \cdot i_{F}(t) \cdot d t \\
& =V_{D} \cdot I_{F, a v g}+R_{D} \cdot I_{F, r m s}^{2}
\end{aligned}
$$

where $V_{D}$ is diode forward voltage, $i_{F}$ is current through the diode, $I_{F, \text { avg }}$ is the average value of diode current, and $I_{F, r m s}$ is the root mean square value of the diode current.

Switching losses consist of turn-on and turn-off switching sequences, which depends upon rise and fall times, the number of active switches, and switching frequency. The switching losses are analyzed for a typical switch, and then it will be extended for the proposed topology. The switching energy losses during the turn-on state in the MOSFET $\left(E_{o n, M}\right)$ with taking the reverse recovery of the free-wheeling diode into account can be calculated as follows:

$$
\begin{aligned}
E_{\text {on, } M} & =\int_{0}^{T_{r i}+T_{f v}} v_{D S}(t) \cdot i_{D S}(t) \cdot d t \\
& =V_{D S} \cdot I_{D S, o n} \cdot \frac{T_{r i}+T_{f v}}{2}+Q_{r r} \cdot V_{D S}
\end{aligned}
$$

where $T_{r i}$ is the current rise-time of the switch, $T_{v f}$ is the voltage fall-time of the switch, $v_{D S}$ is the drain-source voltage, $I_{D S \text {,on }}$ is the drain-source current in on-state and $Q_{r r}$ is the reverse recovery charge. It should be considered that at low switching frequencies the switching losses are very small.

The switching losses during the turn-off state $\left(E_{o f f, M}\right)$ is as follows: 


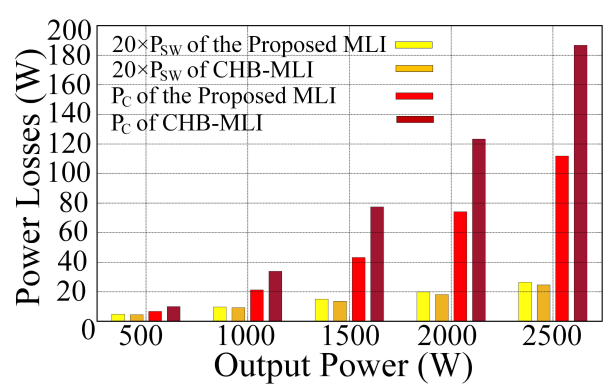

(a)

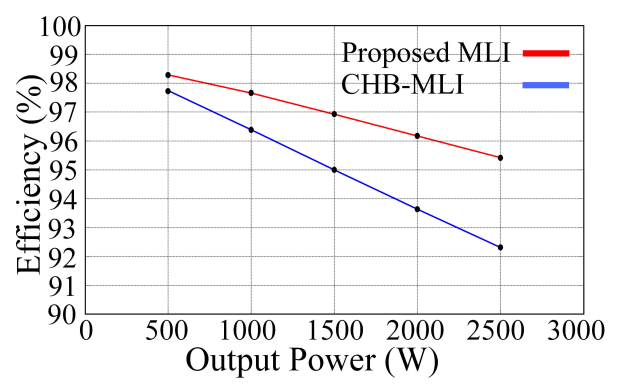

(b)

Fig. 6. Efficiency analysis of the proposed topology and the conventional CHB-MLI topologies with 15-level output voltage, (a) Conduction and switching losses distribution, (b) Simulated efficiency at different output powers.

$$
\begin{aligned}
E_{o f f, M} & =\int_{0}^{T_{r v}+T_{f i}} v_{D S}(t) \cdot i_{D S}(t) \cdot d t \\
& =V_{D S} \cdot I_{D S, o f f} \cdot \frac{T_{r v}+T_{f i}}{2}
\end{aligned}
$$

where $T_{r v}$ is the voltage rise-time of the switch, $T_{f i}$ is the current fall-time of the switch, and $I_{D S, o f f}$ is the drain-source current in off-state. Turn-on and turn-off energy of the diode that consists mostly of the reverse-recovery energy is normally neglected.

Finally, power losses and efficiency equations can be calculated as follows:

$$
\begin{gathered}
P_{s w}=\left(E_{o f f, M}+E_{o n, M}\right) \cdot F_{s w} \\
P_{\text {loss }}=P_{c, M}+P_{c, D}+P_{s w} \\
\eta=\frac{P_{\text {out }}}{P_{\text {out }}+P_{\text {loss }}} \cdot 100 \%
\end{gathered}
$$

Here $P_{s w}$ is the switching losses, $P_{l o s s}$ is the total power losses, $P_{\text {out }}$ is the output power, and $F_{s w}$ is the fundamental

TABLE IV

UTILIZED POWER MOSFET SPECIFICATIONS

\begin{tabular}{ll}
\hline \hline Parameter & Value \\
\hline$R_{D S, \text { on }}$ & $0.027 \Omega$ \\
$R_{D}$ & $0.05 \Omega$ \\
$V_{D}$ & $1.8 \mathrm{~V}$ \\
$T_{r i} \cong T_{r v}$ & $55 \mathrm{~ns}$ \\
$T_{f i} \cong T_{f v}$ & $39 \mathrm{~ns}$ \\
$Q_{r r}$ & $5 \mu \mathrm{C}$ \\
Junction Temperature & $25{ }^{\circ} \mathrm{C}$ \\
\hline \hline
\end{tabular}

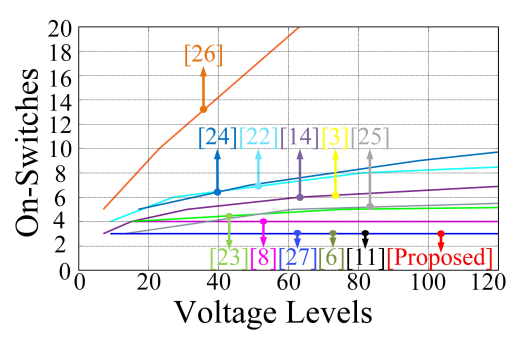

(a)

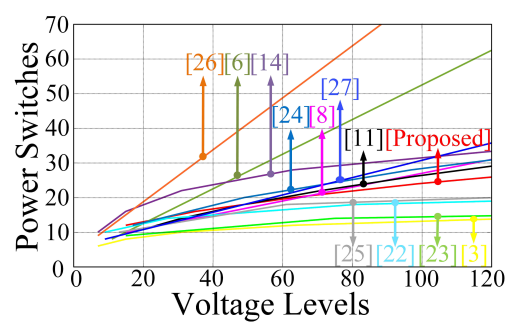

(b)

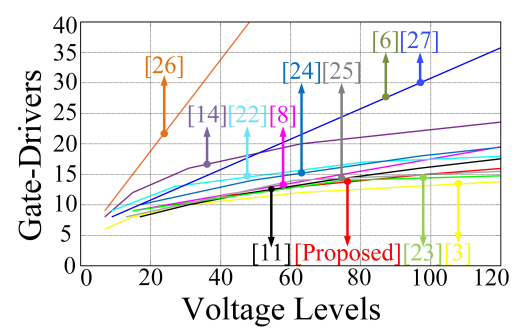

(c)

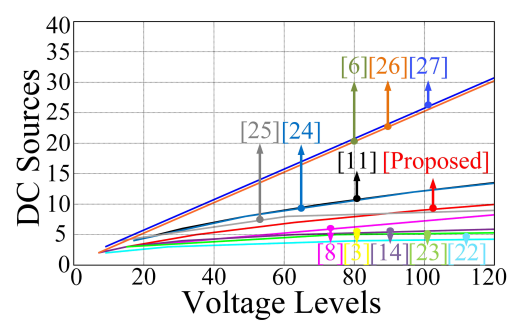

(d)

Fig. 7. Comparison of different topologies (a) On-state power switches, (b) Power switches, (c) Gate-drivers, (d) DC sources, against the voltage levels.

switching frequency. The aforementioned losses are obtained numerically for the proposed MLI topology and CHB-MLI according to the power MOSFETs specification that is presented in Table IV [10].

Table V presents some details of the component count for the proposed topology and the conventional CHB-MLI. In Fig. 6(a), the theoretical calculation of the conduction and the switching losses are depicted for 15-level inverters at different output powers and $V_{r m s}$ of the output voltage magnitude is equal to $0.71 \mathrm{pu}$. The binary manner is used in CHBMLI topology. Both of these topologies have twelve power switches and three DC sources. In this figure, the switching losses are multiplied by 20 to be observable. It can be seen that conduction losses have the most contribution to the total power loss. In Fig. 6(b), the theoretical efficiency for a 15level proposed topology and CHB-MLI topology is presented. It can be seen, the proposed MLI topology and CHB-MLI efficiencies are about $98.3 \%$ and $97.4 \%$ respectively for 500 


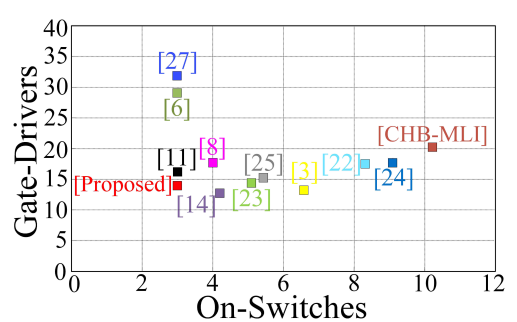

(a)

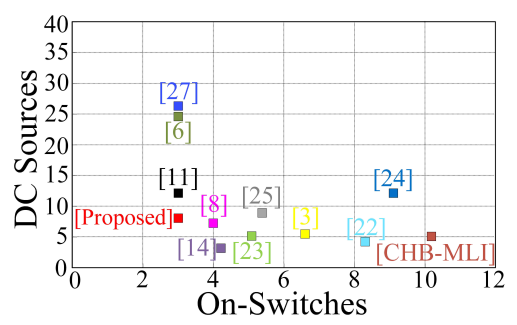

(b)

Fig. 8. Comparison of different topologies with the same number of switching patterns (a) Gate-drivers and (b) DC sources, against the on-state power switches.

W output power, and it is about $95.4 \%$ and $92.2 \%$ respectively for $2.5 \mathrm{~kW}$ output power. It is clear, the proposed MLI topology has lower power losses and higher efficiency than the conventional CHB-MLI.

\section{COMPARISON OF TOPOLOGIES}

To analyze the proposed topology's effectiveness, various comparisons have been made with the number of output voltage levels, on-state switches, switching patterns, power switches, gate-drivers, and DC sources with recent topologies. In the first section comparing diagrams, four different features are assessed, and Fig. 7 shows the relevant charts. Fig. 7(a) shows a graphical representation of the number of on-state switches versus the voltages levels of the proposed MLI topology and other MLI topologies. It can be observed the number of on-state switches of the proposed topology with a modular extension for any level is equal to three. The references [6] and [11] have the same value as the proposed topology, but reference [8] has four on-state switches. This feature leads to fewer component counts in the current path, and finally, fewer conduction losses. As demonstrated in Fig. 7(b), the proposed topology has fewer power switches against the reference [6] and [14]. Based on Fig. 7(c), the reference [14] has many gatedrivers that consists of isolated DC sources and optocouplers.

TABLE V

Comparison of the Proposed MLI with CHB-MLI [2]

\begin{tabular}{cccc}
\hline \hline Voltage Level & Components & CHB-MLI & Proposed MLI \\
\hline \multirow{4}{*}{15} & Power MOSFETs & 12 & 12 \\
& Optocouplers & 12 & 9 \\
& Isolated Aux DC Sources & 9 & 7 \\
& Power DC Sources & 3 & 3 \\
& DC Source Varieties & 3 & 3 \\
& On-State Switches & 6 & 3 \\
\hline \hline
\end{tabular}

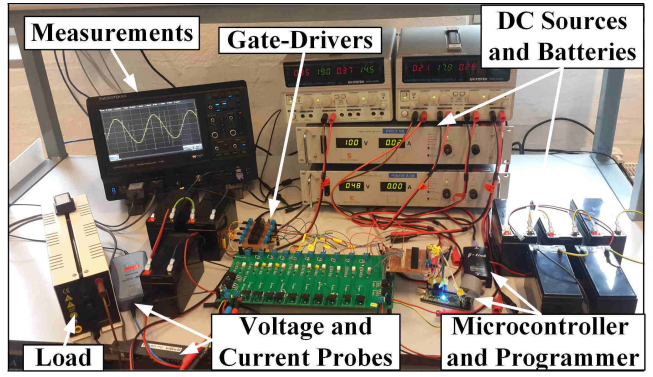

Fig. 9. Laboratory setup for the proposed MLI.

In the proposed topology, bidirectional switches are used that have a common source-emitter. It leads to employing fewer gate-drivers. Fig. 7(d) presents the proposed topology has a reduction in DC sources against [6] and [11] topologies. Reduction in power switches, gate-drivers, and DC sources improves the complexity of control, total cost, volume, and weight.

Investigating the number of switching patterns regarding the reliability and the protection point of view is critical when a fault has occurred. The number of gate-drivers and DC sources are compared against the number of on-state power switches in Fig. 8, and the number of switching patterns are equal to 100 for all the topologies. It can be seen the proposed MLI topology has the minimum number of gate-drivers and DC sources against on-state power switches simultaneously, with the same number of switching patterns, which can change the current path. The number of isolated auxiliary power sources presented in Table $\mathrm{V}$ justifies the proposed topology's additional advantage. In the case of 15 voltage levels, the proposed MLI contains 12 power MOSFETs. At the same time, it requires only seven auxiliary isolated DC sources for the drivers' power supply. These results from the fact that ten out of twelve MOSFETs feature common-source connections in five pairs, as could be appreciated from Fig. 1. Moreover, these pairs of MOSFETs could be driven using a single 2-channel low-side driver to reduce converter realization complexity. These features reduce the number and cost of components in auxiliary circuits of the proposed MLI.

\section{Vi. Simulation and Experimental Results}

To demonstrate the proposed topology, it has been implemented in MATLAB/SIMULINK as well as the prototype.

TABLE VI

HARDWARE SPECIFICATIONS

\begin{tabular}{ll}
\hline \hline Components & Specifications \\
\hline Microcontroller & ARM (NXP-LPC 1768) \\
MOSFET & IRFP460 \\
Optocoupler & TLP250 \\
DC/DC Converter & R12P22005D \\
Battery & RS PRO, 12V Lead, 7Ah \\
Input Voltage (15-Level) & $D C_{1}=84 \mathrm{~V}, D C_{2}=210 \mathrm{~V}, D C_{L 1}=42 \mathrm{~V}$ \\
Input Voltage (25-Level) & $D C_{1}=52 \mathrm{~V}, D C_{2}=260 \mathrm{~V}$, \\
& $D C_{L 1}=26 \mathrm{~V}, D C_{R_{1}^{\prime}}=130 \mathrm{~V}$ \\
Load & $100 \Omega<\mathrm{R}<500 \Omega$ \\
Output Frequency & $50 \mathrm{~Hz}$ \\
\hline \hline
\end{tabular}




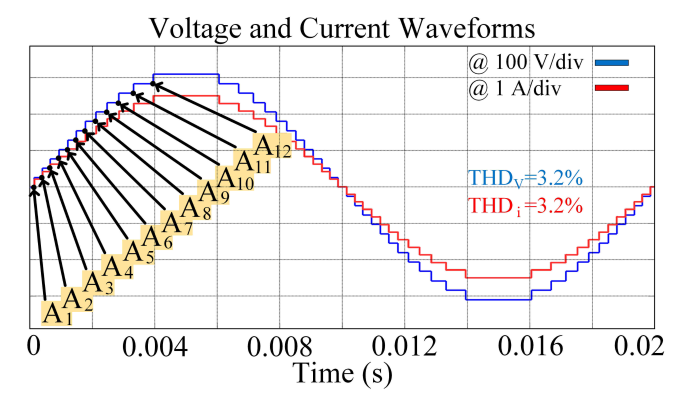

(a)

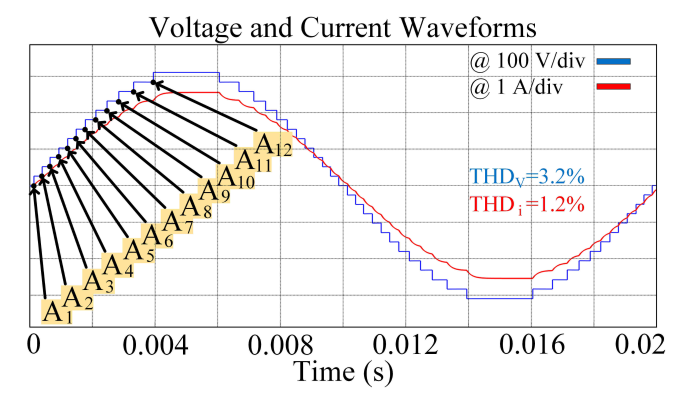

(b)

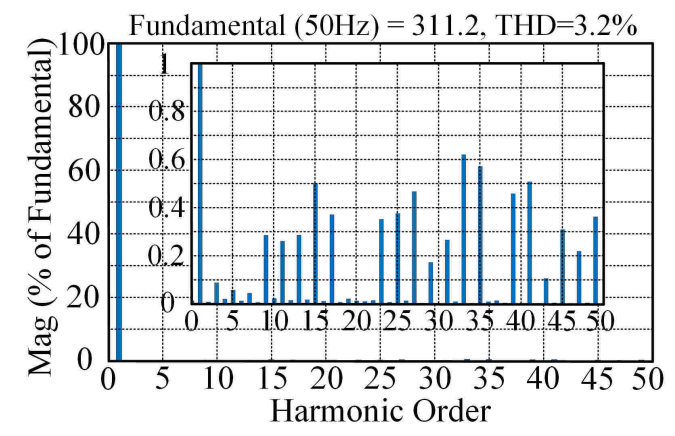

(c)

Fig. 10. Simulation results of 25-level MLI with optimized switching angles, (a) Output voltage and current waveforms for resistance load, (b) Output voltage and current waveforms for resistive-inductor load, (c) Simulated spectrum of low order harmonics in the output voltage.

Specifications of the hardware prototype are given in Table VI. In this experiment, batteries are utilized as bidirectional DC sources to generate output voltage levels. ARM microcontroller (NXP-LPC 1768) is employed to generate the switching sequences. The experimental setup of the MLI topology prototype is depicted in Fig. 9. Simulation results of the proposed topology using a 25-level inverter with optimized twelve switching angles based on Table III are presented in Fig. 10. The stepped waveforms of the output voltage and current are presented in Fig. 10(a) for a resistance load equal to $120 \Omega$. Both the $\mathrm{THD}_{\mathrm{V}}$ and $\mathrm{THD}_{\mathrm{i}}$ of the output are equal to $3.2 \%$ and $V_{r m s}$ is equal to $0.72 \mathrm{pu}$. In Fig. 10(b), the stepped waveforms of the output voltage and current for a resistiveinductor load that comprises $120 \Omega$ and $20 \mathrm{mH}$ are presented. The $\mathrm{THD}_{\mathrm{V}}$ and $\mathrm{THD}_{\mathrm{i}}$ of the output are equal to $3.2 \%$ and $1.2 \%$ respectively, and $V_{r m s}$ is equal to $0.72 \mathrm{pu}$ too. Also, the harmonic spectrum of the output voltage is presented in Fig. 10 (c). The ratio of the value for the DC voltage sources of the proposed 25-level are $D C_{1}=2 V_{D C}, D C_{2}=10 V_{D C}$, $D C_{L 1}=V_{D C}$, and $D C_{R 1^{\prime}}=5 V_{D C}$. Various values are
Voltage and Current Waveforms

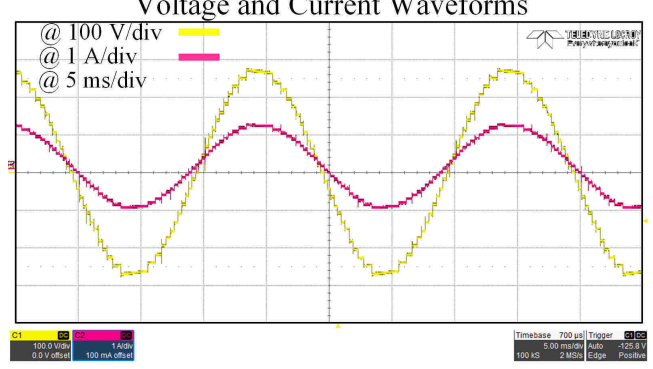

(a)

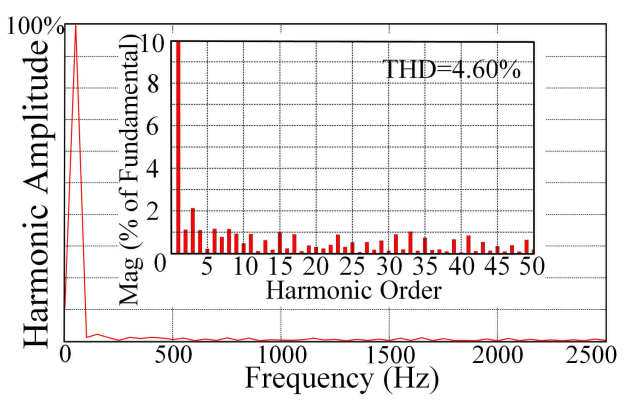

(b)

Fig. 11. Experimental results of the proposed 25-level inverter, (a) Output voltage and current waveforms, (b) Harmonic spectrum.

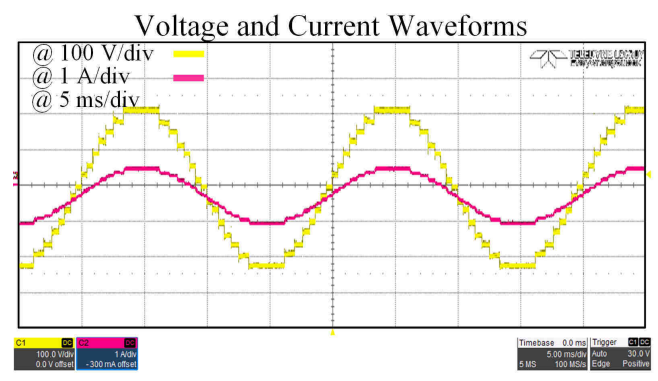

(a)

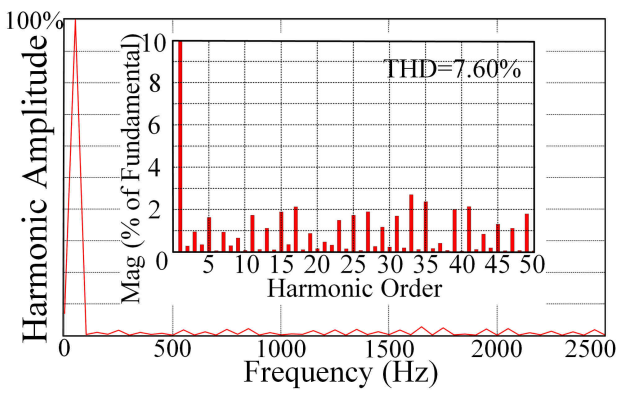

(b)

Fig. 12. Experimental results of the proposed 15-level inverter, (a) Output voltage and current waveforms, (b) Harmonic spectrum.

obtained for the ratio of the DC sources. These values are achieved using the optimization procedure given in Fig. 3. The switching angles of both the simulation and experimental are optimized, as shown in Table III.

Fig. 11(a) and (b) show experimental results of the output voltage and current waveforms with resistance load for 25level proposed MLI. In Fig. 11(a), $V_{r m s}$ is equal to 0.72 $\mathrm{pu}$, and the nominal DC voltage $\left|V_{D C}\right|$ of the output voltage 


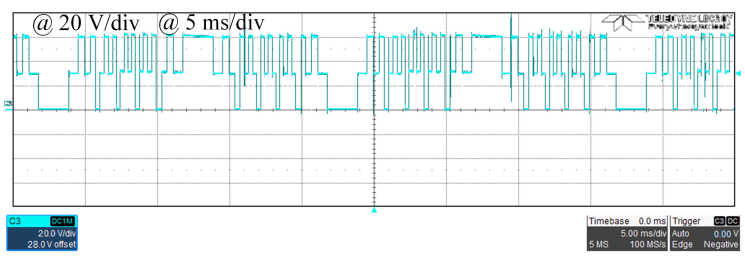

(a)

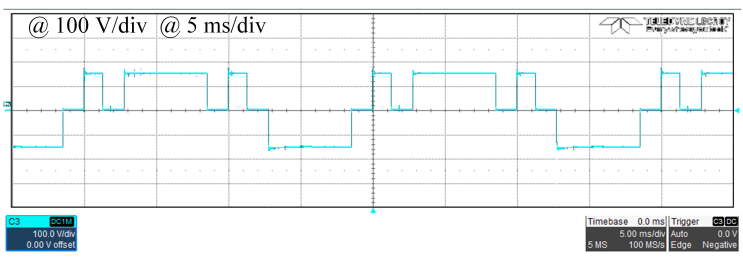

(b)

Fig. 13. Experimental waveforms of voltage across switches for 25-level inverter, (a) $S_{L 1}$, (b) $S_{R 1^{\prime}}$.

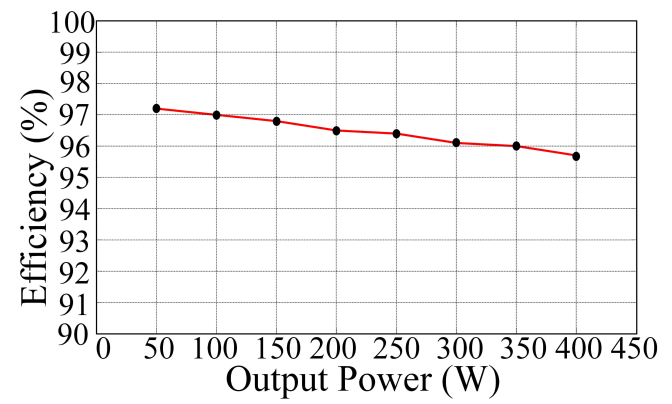

Fig. 14. Measured efficiency of the proposed 15-level inverter topology.

should have the same amplitude that is equal to $26 \mathrm{~V}$. Two sub-cells are considered for the proposed 25 -level inverter. The harmonic spectrum of the output voltage is presented in Fig. 11(b). Details of the harmonic orders and their magnitudes are obtained using an oscilloscope WaveSurfer 3024 (the output voltage waveform is sampled with $100 \mathrm{MS} / \mathrm{s}$ ratio). The obtained samples were transferred to MATLAB software to form the output waveform and measure the harmonic orders.

Fig. 12(a) and (b) present the experimental results of the obtained 15-level output voltage and current waveforms with resistivity load. In Fig. 12(a), the nominal DC voltage $\left|V_{D C}\right|$ of the output voltage has the same amplitude of $42 \mathrm{~V}$, and $V_{r m s}$ is equal to $0.71 \mathrm{pu}$. Only one sub-cell is considered for the proposed 15-level inverter. The harmonic spectrum of the output voltage is presented in Fig. 12(b). Due to the time-delays of components, some even harmonic orders are generated in the harmonic spectrum for both 15- and 25-level inverters.

Measured blocking voltages of $S_{L 1}$ and $S_{R 1^{\prime}}$ bidirectional switches for the proposed 25-level inverter are shown in Fig. 13. These bidirectional switches avoid short circuit of the DC sources. Fig. 14 shows the experimental efficiency versus the output power for the proposed topology with 15-levels. As the output power rises, losses of the whole system will decrease. The efficiency for $50 \mathrm{~W}$ output power is a bit more than $97 \%$, and $400 \mathrm{~W}$ output power is a bit less than $96 \%$. Switching angles of all results for the proposed topology are optimized based on the optimization procedure of Fig. 5.

Evaluation parameters of the proposed topology for modular extension are presented in Table VII. Some parameters, like the required components, switching patterns, voltage levels, TBV, and varieties, are presented. An improved $\mathrm{THD}_{\mathrm{V}}$ is obtained using the OSA modulation strategy for various voltage levels, and it is presented in Table VII.

TABLE VII

Modular EXTENSION OF THE PROPOSED MLI TOPOLOGY

\begin{tabular}{cccccccccc}
\hline \hline Level & $\begin{array}{c}\text { DC } \\
\text { Sources }\end{array}$ & $\begin{array}{c}\text { Unidirectional Bidirectional } \\
\text { Switches }\end{array}$ & $\begin{array}{c}\text { Gate- } \\
\text { Switches }\end{array}$ & $\begin{array}{c}\text { Switching } \\
\text { Drivers }\end{array}$ & Patterns & \multicolumn{1}{c}{$\begin{array}{c}\text { DC Source } \\
\text { Varieties }\end{array}$} & THD & \multirow{2}{*}{$\mathbf{V}_{\text {rms,pu }}$} \\
\hline 15 & 3 & 6 & 3 & 9 & 24 & 36 & 3 & $5.3 \%$ & 0.71 \\
25 & 4 & 6 & 4 & 10 & 36 & 63 & 4 & $3.2 \%$ & 0.72 \\
35 & 5 & 6 & 5 & 11 & 48 & 121 & 4 & $2.5 \%$ & 0.71 \\
49 & 6 & 6 & 6 & 12 & 64 & 176 & 4 & $1.9 \%$ & 0.71 \\
63 & 7 & 6 & 7 & 13 & 80 & 214 & 5 & $1.1 \%$ & 0.71 \\
81 & 8 & 6 & 8 & 14 & 100 & 302 & 6 & $\ldots<1 \%$ & 0.71 \\
99 & 9 & 6 & 9 & 15 & 120 & 412 & 6 & $\ldots<1 \%$ & 0.71 \\
121 & 10 & 6 & 10 & 16 & 144 & 533 & 6 & $\ldots<1 \%$ & 0.71 \\
\hline \hline
\end{tabular}

\section{CONCLUSION}

In this paper, a novel asymmetrical MLI with a reduced component count is proposed to be used for renewable energy generation. The proposed topology can be easily extended to a three-phase structure and both modular and cascaded connections. It can be used in high voltage applications to lower stresses on the power switches. The significant advantage of the proposed MLI is the ability to generate negative voltage levels without a series $\mathrm{H}$-bridge module that gives a reduction in power losses. Only three on-state power switches are required to generated different voltage levels in a module. An optimization procedure is used to determine the magnitude of the DC sources by employing the PSO algorithm to reduce the total blocking voltage instead of common approaches or algorithms. The proposed optimization approach is one of the desired features allowing for considering all the possible combinations of the input DC sources in the output voltage levels. Besides, it is flexible to be applied to any MLI topologies. Moreover, the OSA modulation technique was used at low switching frequency with the optimized switching angles by the PSO algorithm. The obtained optimized switching angles provide the best THD among those in recent papers. Considering power losses, the proposed topology has a reduced number of required switches, gate-drivers, and DC sources for a specific number of voltage levels compared to other MLI topologies. A detailed comparison of the proposed topology with other existing MLI topologies using several indices is performed. It can be concluded that the proposed topology has superior performance and fewer losses compare to published topologies. Abilities of the proposed topology are verified by simulations and experiments with 15- and 25-level inverters.

\section{REFERENCES}

[1] J. S. M. Ali and V. Krishnaswamy, "An assessment of recent multilevel inverter topologies with reduced power electronics components for renewable applications," Renewable and Sustainable Energy Reviews, vol. 82, pp. 3379-3399, 2018. 
[2] P. R. Bana, K. P. Panda, R. Naayagi, P. Siano, and G. Panda, "Recently developed reduced switch multilevel inverter for renewable energy integration and drives application: topologies, comprehensive analysis and comparative evaluation," IEEE Access, vol. 7, pp. 54 888-54909, 2019.

[3] K. Boora and J. Kumar, "A novel cascaded asymmetrical multilevel inverter with reduced number of switches," IEEE Transactions on Industry Applications, vol. 55, no. 6, pp. 7389-7399, 2019.

[4] S. S. Lee, "Single-stage switched-capacitor module (s $3 \mathrm{~cm}$ ) topology for cascaded multilevel inverter," IEEE Transactions on Power Electronics, vol. 33, no. 10, pp. 8204-8207, 2018.

[5] K. Boora and J. Kumar, "General topology for asymmetrical multilevel inverter with reduced number of switches," IET Power Electronics, vol. 10, no. 15, pp. 2034-2041, 2017.

[6] M. D. Siddique, S. Mekhilef, N. M. Shah, and M. A. Memon, "Optimal design of a new cascaded multilevel inverter topology with reduced switch count," IEEE Access, vol. 7, pp. 24 498-24 510, 2019.

[7] M. Saeedian, M. E. Adabi, S. M. Hosseini, J. Adabi, and E. Pouresmaeil, "A novel step-up single source multilevel inverter: Topology, operating principle, and modulation," IEEE Transactions on Power Electronics, vol. 34, no. 4, pp. 3269-3282, 2018.

[8] M. D. Siddique, S. Mekhilef, N. M. Shah, A. Sarwar, A. Iqbal, and M. A. Memon, "A new multilevel inverter topology with reduce switch count," IEEE Access, vol. 7, pp. 58 584-58 594, 2019.

[9] S. S. Lee, M. Sidorov, C. S. Lim, N. R. N. Idris, and Y. E. Heng, "Hybrid cascaded multilevel inverter (hcmli) with improved symmetrical 4-level submodule," IEEE Transactions on Power Electronics, vol. 33, no. 2, pp. 932-935, 2017.

[10] D. Graovac, M. Purschel, and A. Kiep, "Mosfet power losses calculation using the data-sheet parameters," Infineon application note, vol. 1, pp. $1-23,2006$.

[11] R. S. Alishah, S. H. Hosseini, E. Babaei, and M. Sabahi, "Optimal design of new cascaded switch-ladder multilevel inverter structure," IEEE Transactions on Industrial Electronics, vol. 64, no. 3, pp. 20722080, 2016.

[12] T. Adefarati and R. Bansal, "Integration of renewable distributed generators into the distribution system: a review," IET Renewable Power Generation, vol. 10, no. 7, pp. 873-884, 2016.

[13] M. Saeedian, J. Adabi, and S. M. Hosseini, "Cascaded multilevel inverter based on symmetric-asymmetric dc sources with reduced number of components," IET Power Electronics, vol. 10, no. 12, pp. 1468-1478, 2017.

[14] K. Gupta and S. Jain, "Topology for multilevel inverters to attain maximum number of levels from given dc sources," IET Power Electronics, vol. 5, no. 4, pp. 435-446, 2012.

[15] A. Yahya, S. M. U. Ali, and A. Ghani, "New level doubling architecture of cascaded multilevel inverter," IET Power Electronics, vol. 12, no. 8, pp. 1891-1902, 2019.

[16] S. H. L. Majareh, F. Sedaghati, M. Hosseinpour, and S. R. MousaviAghdam, "Design, analysis and implementation of a generalised topology for multilevel inverters with reduced circuit devices," IET Power Electronics, vol. 12, no. 14, pp. 3724-3731, 2019.

[17] R. Choupan, S. Golshannavaz, D. Nazarpour, and M. Barmala, "A new structure for multilevel inverters with fault-tolerant capability against open circuit faults," Electric Power Systems Research, vol. 168, pp. 105116, 2019.

[18] A. Karthik and U. Loganathan, "A reduced component count five-level inverter topology for high reliability electric drives," IEEE Transactions on Power Electronics, vol. 35, no. 1, pp. 725-732, 2019.

[19] H. N. Avanaki, R. Barzegarkhoo, E. Zamiri, Y. Yang, and F. Blaabjerg, "Reduced switch-count structure for symmetric multilevel inverters with a novel switched-dc-source submodule," IET Power Electronics, vol. 12, no. 2, pp. 311-321, 2018.

[20] M. Ghodsi and S. M. Barakati, "A generalized cascade switchedcapacitor multilevel converter structure and its optimization analysis," IEEE Journal of Emerging and Selected Topics in Power Electronics, 2019.

[21] S. T. Meraj, K. Hasan, and A. Masaoud, "A novel configuration of cross-switched t-type (ct-type) multilevel inverter," IEEE Transactions on Power Electronics, vol. 35, no. 4, pp. 3688-3696, 2019.

[22] N. Prabaharan, Z. Salam, C. Cecati, and K. Palanisamy, "Design and implementation of new multilevel inverter topology for trinary sequence using unipolar pulsewidth modulation," IEEE Transactions on Industrial Electronics, vol. 67, no. 5, pp. 3573-3582, 2019.

[23] S. Majumdar, B. Mahato, and K. C. Jana, "Implementation of an optimum reduced components multicell multilevel inverter (mc-mli) for lower standing voltage," IEEE Transactions on Industrial Electronics, vol. 67, no. 4, pp. 2765-2775, 2019.

[24] R. S. Alishah, S. H. Hosseini, E. Babaei, and M. Sabahi, "A new general multilevel converter topology based on cascaded connection of submultilevel units with reduced switching components, dc sources, and blocked voltage by switches," IEEE Transactions on Industrial Electronics, vol. 63, no. 11, pp. 7157-7164, 2016.

[25] R. S. Alishah, S. H. Hosseini, E. Babaei, and M. Sabahi, "Optimization assessment of a new extended multilevel converter topology," IEEE Transactions on Industrial Electronics, vol. 64, no. 6, pp. 4530-4538, 2017.

[26] R. S. Alishah, K. Bertilsson, F. Blaabjerg, M. A. J. Sathik, and A. Y. Rezaee, "New grid-connected multilevel boost converter topology with inherent capacitors voltage balancing using model predictive controller," in 2020 22nd European Conference on Power Electronics and Applications (EPE'20 ECCE Europe), pp. 1-7. IEEE, 2020.

[27] R. Shalchi Alishah, K. Bertilsson, S. H. Hosseini, E. Babaei, M. Aalami, J. S. Mohed Ali, and G. B. Gharehpetian, "A new generalized cascade multilevel converter topology and its improved modulation technique," International Journal of Circuit Theory and Applications, 2020.

[28] N. Prabaharan and K. Palanisamy, "A comprehensive review on reduced switch multilevel inverter topologies, modulation techniques and applications," Renewable and Sustainable Energy Reviews, vol. 76, pp. 12481282, 2017.

[29] M. S. O. Yeganeh, M. Sarvi, F. Blaabjerg, and P. Davari, "Improved harmonic injection pulse-width modulation variable frequency triangular carrier scheme for multilevel inverters," IET Power Electronics, 2020.

[30] K. P. Panda and G. Panda, "Application of swarm optimisation-based modified algorithm for selective harmonic elimination in reduced switch count multilevel inverter," IET Power Electronics, vol. 11, no. 8, pp. 1472-1482, 2018.

[31] K. P. Panda, S. S. Lee, and G. Panda, "Reduced switch cascaded multilevel inverter with new selective harmonic elimination control for standalone renewable energy system," IEEE Transactions on Industry Applications, vol. 55, no. 6, pp. 7561-7574, 2019.

[32] P. K. Kar, A. Priyadarshi, and S. B. Karanki, "Selective harmonics elimination using whale optimisation algorithm for a single-phasemodified source switched multilevel inverter," IET Power Electronics, vol. 12, no. 8, pp. 1952-1963, 2019.

[33] C. M. Van, T. N. Xuan, P. V. Hoang, M. T. Trong, S. P. Cong, and L. N. Van, "A generalized space vector modulation for cascaded hbridge multi-level inverter," in 2019 International Conference on System Science and Engineering (ICSSE), pp. 18-24. IEEE, 2019.

[34] M. S. O. Yegane and M. Sarvi, "An improved harmonic injection pwm-frequency modulated triangular carrier method with multiobjective optimizations for inverters," Electric Power Systems Research, vol. 160, pp. 372-380, 2018.

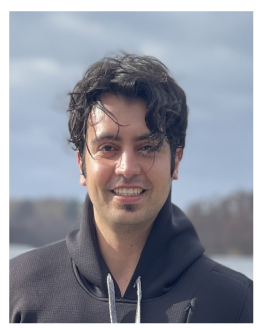

Mohammad Sadegh Orfi Yeganeh was born in Hamadan, Iran. He received the B.Sc. degree from Bu-Ali Sina University, Hamadan, Iran, in 2014 and the M.Sc. degree from Imam Khomeini International University, Qazvin, Iran, in 2016, both in electrical engineering. He was also a guest researcher for a year from 2019 at the Department of Energy Technology, Aalborg University, Denmark. He is currently working toward a Ph.D. degree at the electrical engineering department, Technical University of Denmark.

His interest areas include power electronics and its applications, power converter, reliability, and renewable energies. 


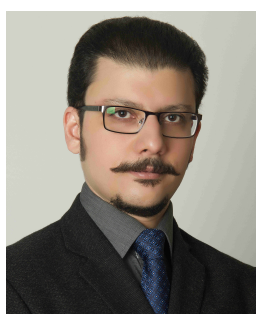

Pooya Davari (S'11-M'13-SM'19) received the B.Sc. and M.Sc. degrees in electronic engineering from University of Mazandaran (Noushirvani), Iran, in 2004 and 2008, respectively, and the Ph.D. degree in power electronics from QUT, Australia, in 2013. From 2005 to 2010 , he was involved in several electronics and power electronics projects as a Development Engineer. From 2013 to 2014, he was with QUT, as a Lecturer. He joined Aalborg University, in 2014, as a Postdoc, where he is currently an Associate Professor.

He has been focusing on EMI, power quality and harmonic mitigation analysis and control in power electronic systems. He has published more than 150 technical papers. Dr. Davari served as a Guest Associate Editor of IET journal of Power Electronics, IEEE Access Journal, Journal of Electronics and Journal of Applied Sciences. He is an Associate Editor of Journal of Power Electronics, Associate Editor of IET Electronics, and Journal of Applied Sciences. He is member of the International Scientific Committee (ISC) of EPE (ECCE Europe) and a member of Joint Working Group six and Working Group eight at the IEC standardization TC77A. Dr. Davari is the recipient of a research grant from the Danish Council of Independent Research (DFFFTP) in 2016, and 2020 IEEE EMC Society Young Professional Award for his contribution to EMI and Harmonic Mitigation and Modeling in Power Electronic Applications. He is currently Editor-in-Chief of Circuit World Journal.

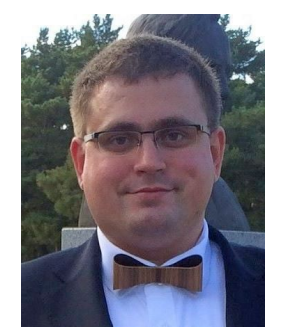

Andrii Chub (Senior Member, IEEE) received the B.Sc. and M.Sc. degrees in electronic systems from the Chernihiv State Technological University, Ukraine, in 2008 and 2009, respectively, and the $\mathrm{Ph} . \mathrm{D}$. degree in electrical engineering from the Tallinn University of Technology, Estonia, in 2016. $\mathrm{He}$ is a Senior Researcher with the Power Electronics Group, Department of Electrical Power Engineering and Mechatronics, Tallinn University of Technology. He was a Visiting Research Fellow with Kiel University in 2017, and a Postdoctoral Researcher at Federico Santa Maria Technical University between 2018 and 2019. $\mathrm{He}$ has co-authored more than 100 papers and a book chapter on power electronics and applications, and holds several patents and utility models. His research interests include advanced dc-dc converter topologies, renewable energy conversion systems for energy-efficient buildings, reliability and faulttolerance of power electronic converters.

Dr. Chub is an Associate Editor for the IEEE Journal of Emerging and Selected Topics in Industrial Electronics. He was the recipient of numerous best paper awards at IEEE conferences and 2018 IEEE Industrial Electronics Society Best Conference Paper Award.

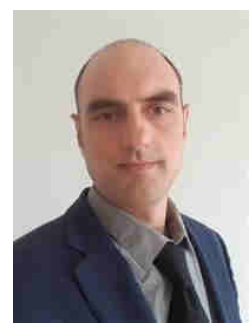

Nenad Mijatovic Nenad Mijatovic after obtaining his Dipl.Ing. education in Electrical Power Engineering at University of Belgrade, Serbia in 2007, was enrolled as a doctoral candidate at Technical University of Denmark. He received his Ph.D. degree from Technical University of Denmark for his work on technical feasibility of novel machines and drives for wind industry. Upon completion of his $\mathrm{PhD}$, he continued work within the field of wind turbine direct-drive concepts as an Industrial PostDoc.

Dr. N. Mijatovic currently holds position of Associate Professor at Technical University of Denmark where he is in charge of managing research projects and education related to the field of electrical machines and drives, power electronic convertors, motion control, application of energy storage and general applications of low frequency electromagnetism and large scale application of superconductivity with main focus on emerging eMobility and renewable energy generation.

$\mathrm{He}$ is a member of IEEE since 2008 and senior member of IEEE since 2018 and his field of interest and research includes novel electrical machine drives/actuator designs, operation, control and diagnostic of electromagnetic assemblies, advance control of drives and grid connected power electronics, energy storage and eMobility.

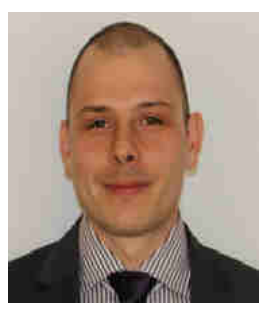

Tomislav Dragičević (S'09-M'13-SM'17) received the M.Sc. and the industrial Ph.D. degrees in Electrical Engineering from the Faculty of Electrical Engineering, University of Zagreb, Croatia, in 2009 and 2013, respectively. From 2013 until 2016 he has been a Postdoctoral researcher at Aalborg University, Denmark. From 2016 until 2020 he was an Associate Professor at Aalborg University, Denmark. Currently, he is a Professor at the Technical University of Denmark.

He made a guest professor stay at Nottingham University, UK during spring/summer of 2018. His research interest is application of advanced control, optimization and artificial intelligence inspired techniques to provide innovative and effective solutions to emerging challenges in design, control and cyber-security of power electronics intensive electrical distributions systems and microgrids. He has authored and coauthored more than 300 technical publications (more than 130 of them are published in international journals, mostly in IEEE), 8 book chapters and a book in the field.

He serves as an Associate Editor in the IEEE TRANSACTIONS ON INDUSTRIAL ELECTRONICS, in IEEE TRANSACTIONS ON POWER ELECTRONICS, in IEEE Emerging and Selected Topics in Power Electronics and in IEEE Industrial Electronics Magazine. Dr. Dragičević is a recipient of the Končar prize for the best industrial PhD thesis in Croatia, a Robert Mayer Energy Conservation award, and he is a winner of an Alexander von Humboldt fellowship for experienced researchers.

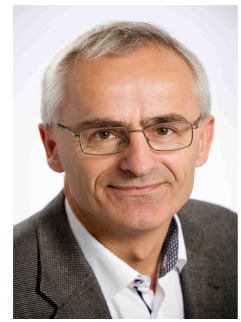

Frede Blaabjerg (S'86-M'88-SM'97-F'03) was with ABB-Scandia, Randers, Denmark, from 1987 to 1988 . From 1988 to 1992 , he got the $\mathrm{PhD}$ degree in Electrical Engineering at Aalborg University in 1995. He became an Assistant Professor in 1992, an Associate Professor in 1996, and a Full Professor of power electronics and drives in 1998. From 2017 he became a Villum Investigator. He is honoris causa at University Politehnica Timisoara (UPT), Romania and Tallinn Technical University (TTU) in Estonia.

His current research interests include power electronics and its applications such as in wind turbines, PV systems, reliability, harmonics and adjustable speed drives. He has published more than 600 journal papers in the fields of power electronics and its applications. He is the co-author of four monographs and editor of ten books in power electronics and its applications.

He has received 33 IEEE Prize Paper Awards, the IEEE PELS Distinguished Service Award in 2009, the EPE-PEMC Council Award in 2010, the IEEE William E. Newell Power Electronics Award 2014, the Villum Kann Rasmussen Research Award 2014, the Global Energy Prize in 2019 and the 2020 IEEE Edison Medal. He was the Editor-in-Chief of the IEEE TRANSACTIONS ON POWER ELECTRONICS from 2006 to 2012. He has been Distinguished Lecturer for the IEEE Power Electronics Society from 2005 to 2007 and for the IEEE Industry Applications Society from 2010 to 2011 as well as 2017 to 2018. In 2019-2020 he served as a President of IEEE Power Electronics Society. He has been Vice-President of the Danish Academy of Technical Sciences. He is nominated in 2014-2020 by Thomson Reuters to be between the most 250 cited researchers in Engineering in the world. 